\title{
Purification of sphalerite concentrate in the chemical and flotation way
}

\author{
Andrzej Jarosiński \\ Cracow University of Technology, Institute of Inorganic Chemistry and Technology, ul. Warszawska 24, 31-155 Kraków, \\ Poland,e-mail: ajar@chemia.pk.edu.pl
}

\begin{abstract}
In this paper the results of the investigation of magnesium removal, from zinc concentrate derived from zinclead ore enrichment plant, have been presented. The characteristics of the initial concentrate and the occurrence forms of dolomite in this material are estimated. It was found that magnesium is collected in the finest fraction of the initial material. The influence of chemical treatment and flotation on the quality improvement of zinc concentrate is determined. This method permits to obtain zinc concentrate containing below $0,3 \% \mathrm{Mg}$ and about $0,7 \% \mathrm{Ca}$.
\end{abstract}

Keywords: zinc concentrates, magnesium removal, chemical treatment and flotation.

\section{INTRODUCTION}

Sphalerite concentrates from domestic zinc and lead ore deposits contain an admixture of dolomite. The presence of this mineral is disadvantageous, particularly for the zinc winning on the hydrometallurgical way. The content of magnesium, amounts even up to about $2,5 \% \mathrm{MgO}$. Taking the practical experience into consideration, above 90 per cent of magnesium included in zinc and lead ores passes to the last production stage i.e. to the process of electrodeposition of zinc from zinc sulfate solution. Magnesium presence in circulating solutions causes deterioration of technical and economic indexes of the electrolysis process and falls off the quality of cathodic zinc. Moreover, high magnesium content in roasted concentrates to be processed has adverse effects on leaching, the viscosity of the solution, filtration and the like.

In industrial praxis two ways of magnesium elimination are recommended. The first way is the systematic collection of a portion of the waste solution from the electrolysis system. The magnesium removal from circulating solutions is feasible but the process is complicated and economically unjustifiable. The second way of decreasing the magnesium content in concentrates is pre-leaching with sulfuric acid. The degree of magnesium and other components decreasing and the rate of leaching are connected with the mineral composition of the initial concentrate, the degree of granularity, the concentration of the used sulfuric acid solution and the like. The content of magnesium in final sphalerite concentrates should be reduced to the level of $0,5-1 \%$.

The results obtained by the authors ${ }^{1-4}$ during their research do prove that the larger part of magnesium passes to the solution as well as the part of zinc and other components included in the initial material. During this chemical treatment gypsum is formed, which decreases the content of zinc in the concentrates and causes some disturbances in the process of zinc obtaining.

For this reason, after the chemical treatment the concentrates are floated for the purpose of their purification from gypsum. The content of some metals in this wastewater exceeds the standard level. Because of this there is the necessity of wastewater purification and processing. The quality requirements for zinc concentrates were presented in the work ${ }^{5}$.
No information about the decreasing of magnesium in sphalerite concentrates by means of leaching with phosphoric acid solutions has been found in literature.

The goal of this work is magnesium removal from sphalerite concentrate in the chemical and flotation way, using phosphoric acid solution as the leaching agent.

\section{EXPERIMENTAL}

In the experiments sphalerite concentrate, obtained during the selective flotation of zinc and lead ores, was used. The studied material was taken from the mechanical preparation department of one of Poland's zinc-lead plants. The chemical composition of the initial material is given in Table 1 . In order to characterize the concentrate, the X-ray investigations with the use of the Philips diffractometer system X Pert and microscopic observations (JEOL JSM 5400) were carried out.

The main leaching experiments were conducted with $100 \mathrm{~g}$ of sphalerite concentrate samples and phosphoric acid solution, containing $10 \% \mathrm{H}_{3} \mathrm{PO}_{4}$. The pulp was stirred with the constant- speed $(80 \mathrm{rate} / \mathrm{min})$ mechanical stirrer fitted with a stainless steel impeller. The solid/liquid mass ratio was equal to $1: 2,5$. The reaction of magnesium and other components removal has been conducted for 2 hours at the temperature $20 \pm 0,1^{\circ} \mathrm{C}$. After the completion of leaching the content of the reaction vessel was then filtered. The solid residue after leaching was dried and dissolved and next analyzed using the ICP method. The filtrate was also analyzed.

The flotation was performed in a $1.5 \mathrm{dm}^{3}$ laboratory flotation cell. The following reagents were used: sodium ethyl xanthate $(\mathrm{EtXNa})$, copper sulfate and pine oil. The data listed are average values from at least three identical experiments.

\section{RESULTS AND DISCUSSION}

The mineral composition of the initial sphalerite concentrate is presented in Fig.1. It can be observed that beside the essential component, that is sphalerite - ZnS, other minerals that occur are: galena $-\mathrm{PbS}$, smithsonite $-\mathrm{ZnCO}_{3}$, dolomite $-\mathrm{Ca}, \mathrm{Mg}\left(\mathrm{CO}_{3}\right)_{2}$ and periclase $-\mathrm{MgO}$.

Table 1. Chemical analysis of the initial zinc concentrate

\begin{tabular}{|l|c|c|c|c|c|c|c|c|}
\hline Component & $\mathrm{Zn}$ & $\mathrm{Pb}$ & $\mathrm{ZnO}^{*}$ & $\mathrm{Fe}$ & $\mathrm{Mg}$ & $\mathrm{Ca}$ & $\mathrm{S}^{* *}$ & $\mathrm{SiO}_{2}$ \\
\hline Content [\%] & 54.29 & 2.80 & 0.48 & 1.13 & 1.14 & 2.17 & 28.7 & 0.76 \\
\hline
\end{tabular}

in the form of carbonate, "* total sulphur 
Table 2. The size and chemical distribution of the studied concentrate

\begin{tabular}{|l|c|rr|r|r|}
\hline \multirow{2}{*}{ Grain size $[\mathrm{mm}]$} & \multirow{2}{*}{ Yield [\%] } & \multicolumn{2}{|c|}{ Content [\%] } & \multicolumn{3}{|c|}{ Recovery [\%] } \\
\hline$<0,04$ & 69.4 & 1.30 & 2.48 & 78.91 & 79.24 \\
$0,04-0,07$ & 7.3 & 0.86 & 1.67 & 5.49 & 5.62 \\
$0.07-0,10$ & 16.5 & 0.57 & 1.03 & 8.23 & 7.83 \\
$0,10-0,20$ & 6.8 & 1.24 & 2.34 & 7.37 & 7.31 \\
\hline Total & 100.0 & & & 100.00 & 100.00 \\
\hline
\end{tabular}

Figure 1. X- ray diffraction pattern of the initial sphalerite concentrate

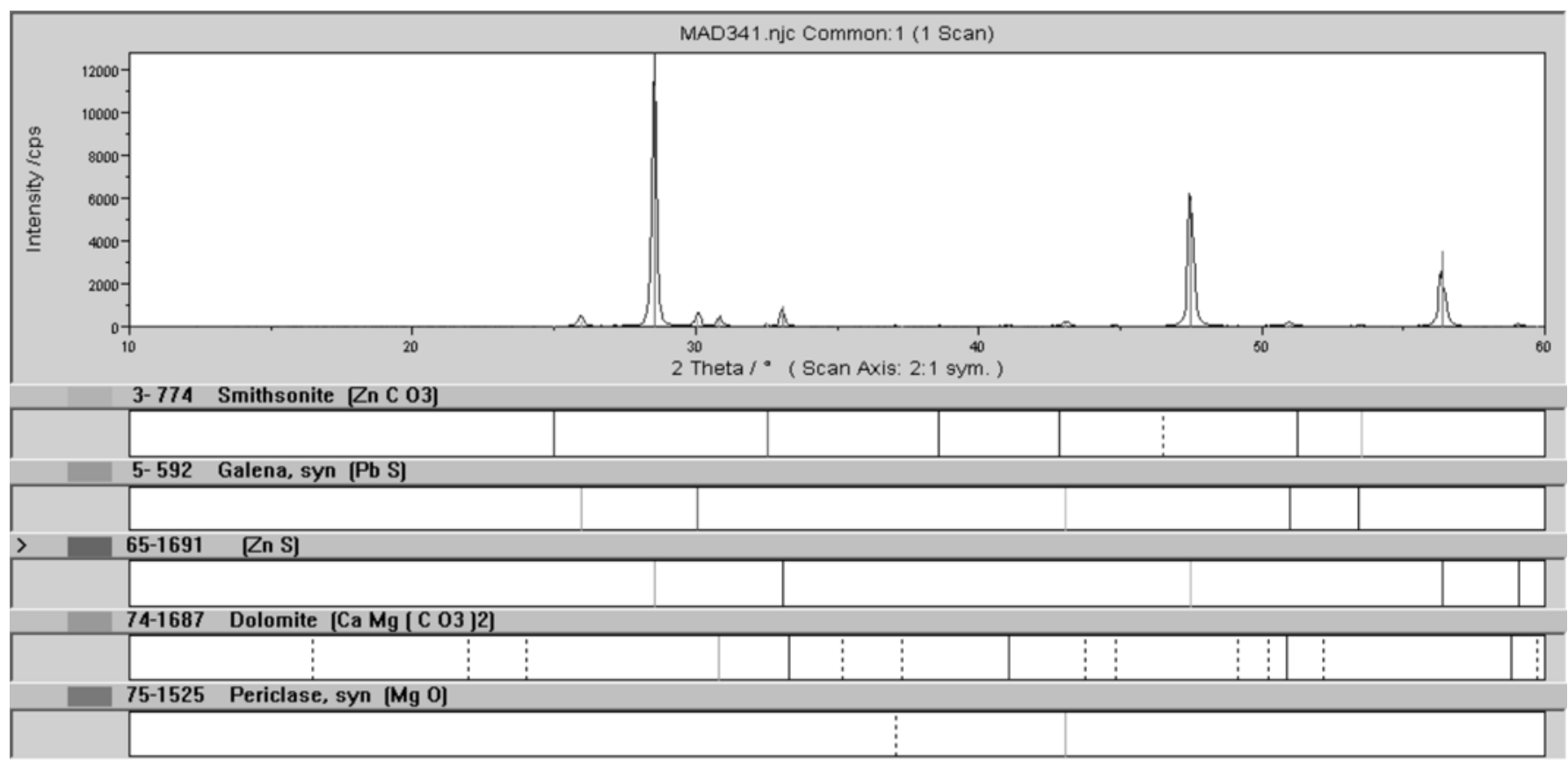

The particle size distribution of the initial material and the contents of magnesium and calcium in respective size fractions are given in Table 2.

The observed distribution is connected with the mineralogical structure of zinc and lead ores deposit as well as the conditions of its mechanical processing. The high yield of finest fraction is disadvantageous because such fraction easily goes to the concentrate and decreases its quality.

The structure of the initial concentrate and the elemental distribution in the grain are shown in Fig.2, 3 and 4. Apart from the main mineral, that is sphalerite of the light-graywhite colour, the second sulphide mineral was galena, also light-gray-white coloured. The dolomite as the gangue mineral in the sphalerite concentrate is visible in the form of the surface that is distinctly darkened. The largest quantity of this mineral was present in the finest size grade. Dolomite occurred in the concentrate in two forms: as free grains, generally not more than $10 \mu \mathrm{m}$ and as intergrowths with sphalerite, intramineral intergrowths included. By this account decreasing of magnesium content in the sphalerite concentrate will not be possible by means of pre-leaching with acid solutions. Decomposition of magnesium phases by acid solution takes place at different rate, so it can be stated that during the pre-leaching process magnesium ions are transferred to the solution in several stages.

The presence of oxidative minerals such as smithsonite in the discussed concentrate is the reason of the zinc loses, because this component is easily soluble, for example, in sulphuric acid. That is the reason of the choice of preleaching parameters, such as: short time of leaching, ambient temperature- because the option may cause limitation of zinc loses, coming up from sphalerite leaching.

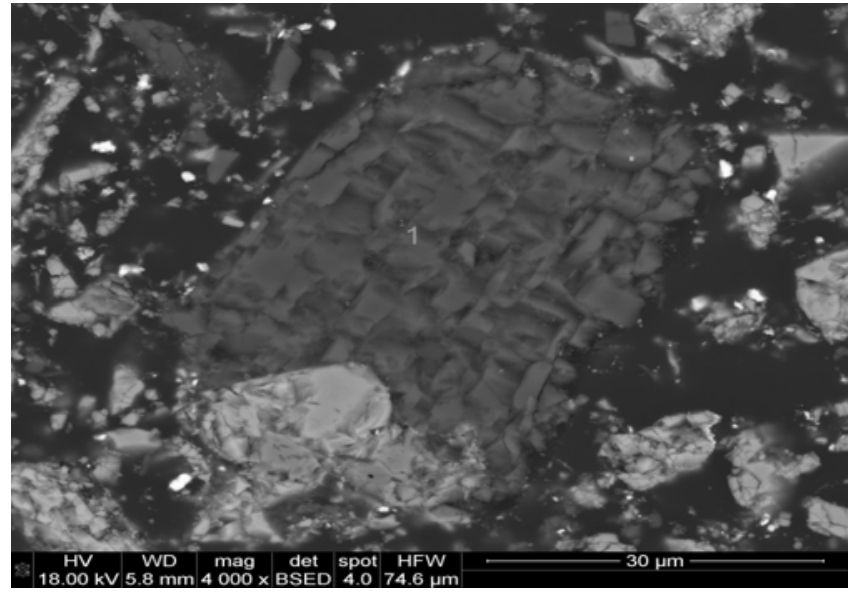

Figure 2. SEM micrograph of the initial sphalerite concentrate

Effect of chemical treatment and flotation on the purification of concentrate

Leaching is based on the decomposition of dolomite with phosphoric acid. The preliminary experimental series were carried out with the $10 \%$ and $20 \% \mathrm{H}_{3} \mathrm{PO}_{4}$ solutions and the leaching time equal to one hour. On the basis of the obtained results it can be stated that magnesium content in the concentrate after leaching lowered to $0,4 \% \mathrm{Mg}$ when $10 \%$ $\mathrm{H}_{3} \mathrm{PO}_{4}$ was used as a leaching agent. The content of magnesium was lower than by used $20 \% \mathrm{H}_{3} \mathrm{PO}_{4}$ solution $(0,52 \% \mathrm{Mg})$. So the main experimental series was conducted using the $10 \%$ phosphoric acid solution for the leaching process. The obtained results indicate that the degree of magnesium leaching increases with increasing the time, for example, after 30 minutes it amounts to $62,89 \%$ and after 


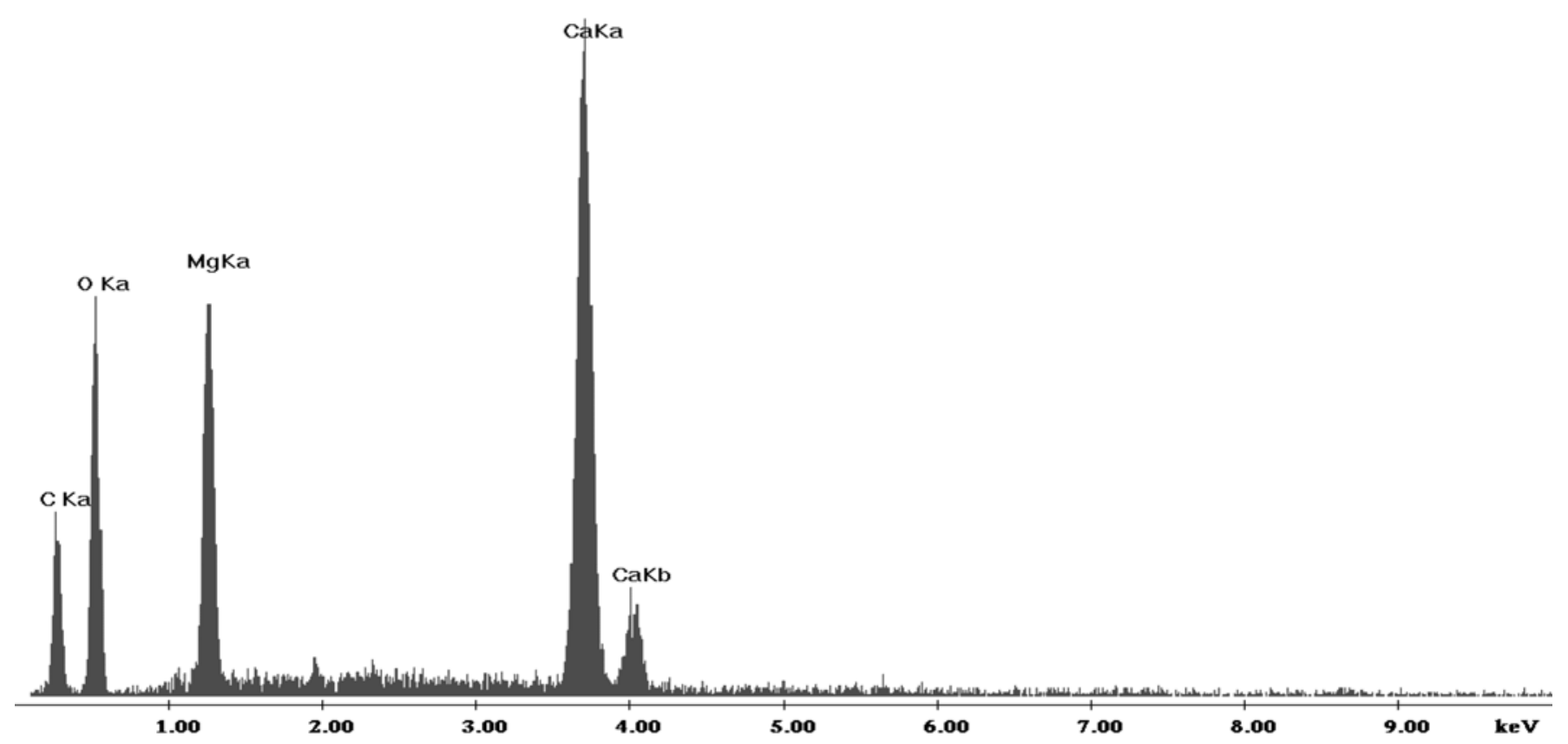

Figure 3. The results of EDS analysis - grain area No.1.

c:ledax32igenesisigenspc.spc

Label A: 1_006p2

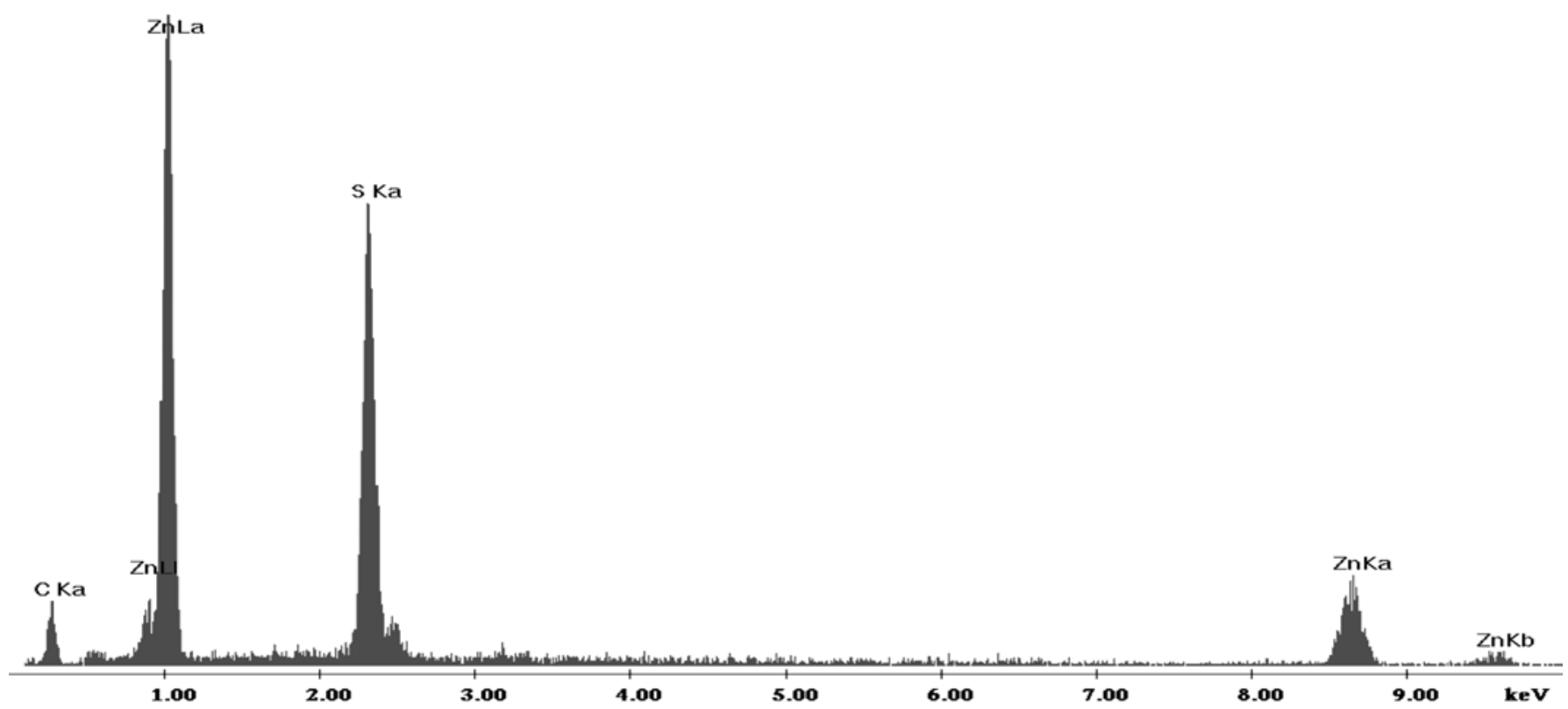

Figure 4. The results of EDS analysis - grain area No.2.

120 minutes to $74,5 \%$. Similarly, the degree of calcium leaching, increases with time, reaching correspondingly the values of $62,94 \%$ after 30 minutes and 76,40 after 120 minutes. The degree of some component leaching after 120 minutes is shown in Table 3. This data indicates that losses of zinc and lead during the chemical treatment were low.

Table 3. The degree of some component leaching after 120 minutes

\begin{tabular}{|c|c|c|c|c|}
\hline Degree of leaching & $\mathrm{Zn}$ & $\mathrm{Pb}$ & $\mathrm{Mg}$ & $\mathrm{Ca}$ \\
\hline Value [\%] & 0.51 & 0.26 & 74.5 & 76.4 \\
\hline
\end{tabular}

Magnesium content in the obtained concentrate after 2 hours amounts to below $0,3 \% \mathrm{Mg}$, which corresponds to technological requirements. In the concentrate after the pre-leaching the presence of $\mathrm{PbHPO}_{4}$ is confirmed (Fig.5). Therefore, in order to purify the concentrate from this lead phase the flotation was used.

The effect of flotation on the removal of magnesium from sphalerite concentrate after the chemical treatment is presented in Fig. 6.

The results of the combined chemical treatment and flotation indicated that this procedure is carried out to further 


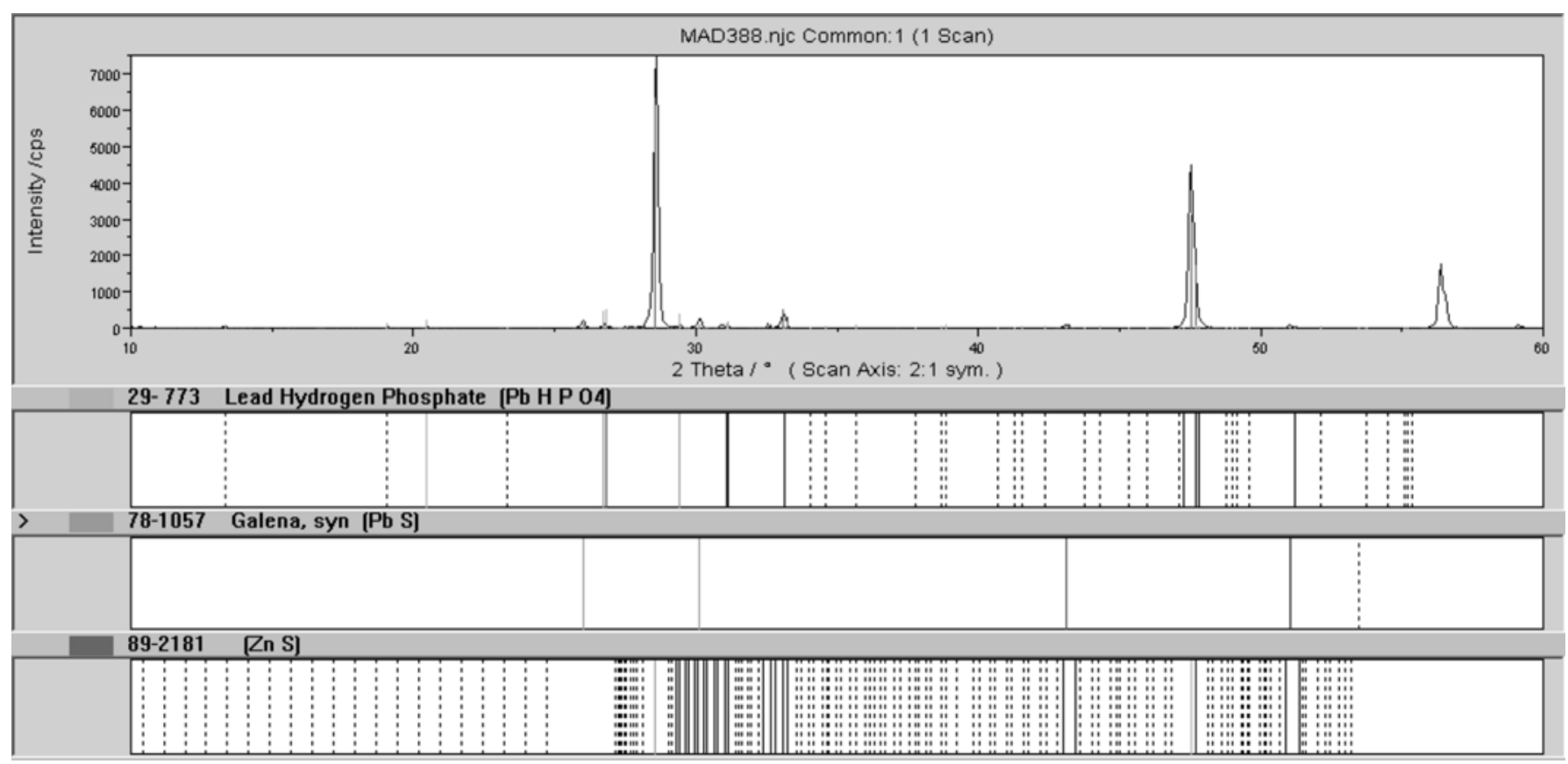

Figure 5. X-ray diffraction pattern of zinc concentrate after leaching

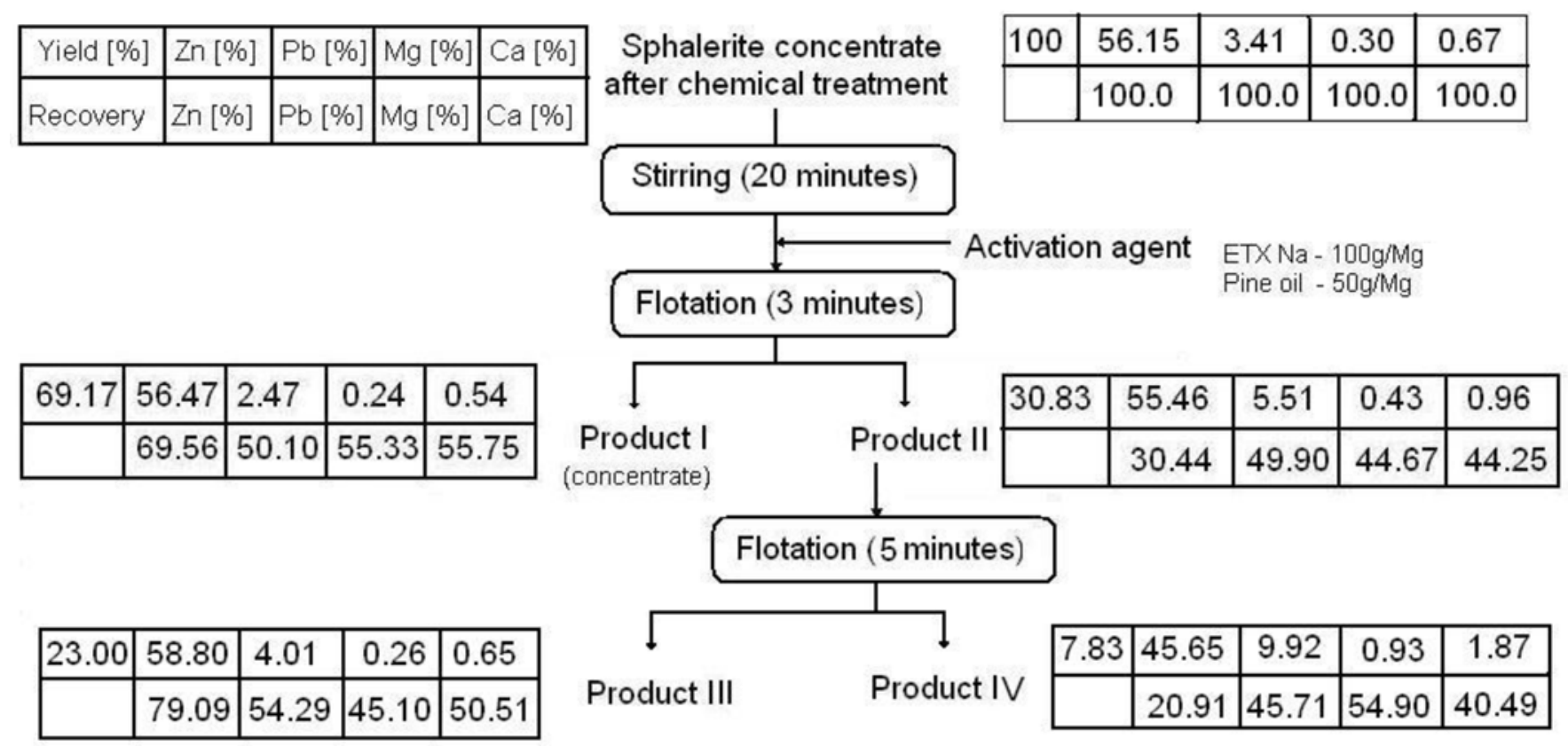

Figure 6. The flowsheet of sphalerite concentrate obtained by means of the preleaching and cleaning flotation

reduce magnesium value in the sphalerite concentrate. Products I and III, obtained by means of flotation enrichment, account for the final sphalerite concentrate. The chemical composition of the final concentrate is given in Table 4. The residual product - product III has its composition comparable to the chemical constitution of the collective concentrates derived from the processing of sulfuric zinc and lead ores (the total content of zinc and lead in the concentrate $\geq 55 \%$ and the ratio of zinc content to lead content about 2 ). This material could be used in the pyrometallurgical process of obtaining zinc.

For the purpose of comparison additional series of investigations were carried out. The initial concentrate of zinc

Table 4. Chemical composition of the final sphalerite concentrate

\begin{tabular}{|l|l|l|l|l|l|}
\hline Component & $\mathrm{Zn}$ & $\mathrm{Pb}$ & $\mathrm{Mg}$ & $\mathrm{Ca}$ & $\mathrm{SiO}_{2}$ \\
\hline Content $[\%]$ & 57.05 & 2.85 & 0.24 & 0.56 & 0.26 \\
\hline
\end{tabular}

leached with the $10 \%$ sulphuric acid solution for $120 \mathrm{~min}$ utes. Next the solid phase floated in order to remove gypsum waste, which was formed during the leaching of initial material. The content of zinc in the final concentrate obtained according to the above procedure amounted to $59,88 \%$.

The degree of enrichment was defined as the ratio of zinc content in the concentrate after leaching and cleaning flotation to zinc content in the initial concentrate amounted to 1,05 . On the contrary, for the concentrate after chemical treatment by means of leaching with the $10 \%$ sulphuric acid and cleaning flotation the above degree reached the value of 1,10 .

The level of impurities content in zinc concentrate obtained by means of chemical treatment, using sulphuric acid or phosphoric acid solutions as leaching agent, as well as the cleaning flotation, is comparable. 


\section{FINAL REMARKS}

In the studied sphalerite concentrate dolomite occurred in such forms as free grains as well as intergrowths with sphalerite. Generally, grains of dolomite were lower than 10 $\mu \mathrm{m}$. Mass fraction below $0,04 \mathrm{~mm}$ in the initial material was predominant.

The degrees of magnesium and calcium removal by means of chemical treatment were high and amounted to over $60 \%$. Losses of zinc and lead were low, which is beneficial for the recovery of zinc ores processing.

The products obtained in the way of purification flotation pose valuable materials to further concentrate processing.

\section{ACKNOWLEDGEMENTS}

This work was supported by the Science and Education Ministry (Poland), Project nr 1 TO9B 11930

\section{LITERATURE CITED}

1. Sanak-Rydlewska, S. \& Małysa, E.(1996). Purification of zinc blende concentrates by chemical flotation treatment to remove magnesium, Archiev of Metallurgy, 41, 435 - 440.

2. Małysa, E. \& Sanak-Rydlewska, S. (1999), Application of chemical methods in processing of zinc-lead ores, New trends in mineral Processing III, Part II VSB-TU 24-26 Jule 1999 (pp. 367 - 373). Ostrava, Czechy.

3. Jarosiński, A. \& Fela, K. (2007). Application of sulphuric acid leaching for magnesium removal from zinc concentrate, Polish Journal of Chemical Technology, 9, 2, 19 - 22.

4. Jarosiński, A. \& Madejska, L. (2007). Magnesium removal from Raw zinc concentrates by leaching, Polish J. of Environmental Studies, 16, 3B, 196 - 199.

5. Jarosiński, A. \& Włodarczyk, B. (2005). Timely trends of gain of zinc and lead concentrates in home industry, Zeszyty Naukowe Politechniki Śląskiej s. Górnictwo, 266, 45 55 (in Polish).

6. Cichy, K., Szołomicki, Z. \& Reguła, C. (2007). New technology in enrichment of zinc and lead ores in „Bolesław” factory, Rudy Metale, 52, 10, 595 - 600 (in Polish).

7. Riesenkampf, W. \& Hamankiewicz, M. (1981). Occur native of dolomite in sphalerite concentrate, Prace Mineralogiczne PAN nr 70, Wyd. Geologiczne, Warszawa, Polska (in Polish). 